\title{
Mudanças morfológicas no trato digestório e composição da dieta de larvas e juvenis do linguado Catathyridium jenynsii no reservatório de Itaipu, rio Paraná, Brasil
}

\author{
Ariane F. de Lima, Maristela C. Makrakis, Michele de F. Gimenes, Sérgio Makrakis, Patrícia S. da Silva \\ \& Lucileine de Assumpção
}

Universidade Estadual do Oeste do Paraná (UNIOESTE), Programa de Pós-Graduação em Recursos Pesqueiros e Engenharia de Pesca, Grupo de Pesquisa em Tecnologia de Produção e Conservação de Recursos Pesqueiros e Hídricos (GETECH), Rua da Faculdade, 645, 85903-000, Toledo, PR. (ariane.f.l@hotmail.com)

\begin{abstract}
Morphological shifts in digestive tract and diet composition of larvae and juveniles of flounder Catathyridium jenynsii from Itaipu Reservoir, Paraná River, Brazil. The objective of this study was to characterize the diet and digestive tract morphology of flounder, Catathyridium jenynsii (Günther, 1862) (Achiridae), in its early stages of life. For analysis of the digestive tract, we used a specimen of each larval stage, pre-flexion to post-flexion, and juvenile. A total of 256 larvae and 16 juveniles, belonging to five classes of standard length was analyzed for diet. Data were collected in the Itaipu Reservoir, Paraná River, Brazil, from September, 2001 to March, 2002, and from September, 2002 to February, 2003. The occurrence and numerical methods were applied for determining the occurrence frequency and numerical frequency of each food item in different standard length (SL) classes. The anterior digestive tract of $C$. jenynsii began to differentiate into the stomach at $4.70 \mathrm{~mm}$ SL (not presented pyloric caeca). Since the stage of pre-flexion, there are three intestinal folds and a lot of grooves in the digestive tract. The dietary analysis showed that the smaller larvae (class 1) had a distinct diet, with dominance of cladocerans (mainly Bosmina hagmanni and Bosminopsis deitersi). For class 2, the copepod Notodiaptomus sp. was important both in number and occurrence, however B. hagmanni also had significant importance in the diet. Already the largest larvae (classes 3 and 4) and juveniles (class 5) showed a similar diet, consuming mainly copepods (Notodiaptomus sp.). Therefore, in this study, larvae of $C$. jenynsii can be considered zooplanktivore, since in all stages of development, copedods and cladocerans dominated the diet. Changes in diet followed the morphological changes of the early stages of $C$. jenynsii.
\end{abstract}

KEYWORDS. Flounder, initial feeding, digestory tract, morphological development.

RESUMO. O objetivo deste trabalho foi caracterizar a dieta e a morfologia do trato digestório do linguado, Catathyridium jenynsii (Günther, 1862) (Achiridae), em seus estágios iniciais de vida. Para análise do trato digestório, foi utilizado um exemplar de cada estágio larval, de préflexão até pós-flexão, e juvenil. Um total de 256 larvas e 16 juvenis, pertencentes a cinco classes de comprimento padrão, foi analisado quanto à dieta. Os dados foram coletados no reservatório de Itaipu, rio Paraná, Brasil, de setembro/2001 a março/2002 e setembro/2002 a fevereiro/2003. Para análise dos dados, foram aplicados os métodos de ocorrência e numérico para a determinação da frequência de ocorrência e numérica de cada item alimentar nas diferentes classes de comprimento padrão. A região anterior do trato digestório de $C$. jenynsii, começou a diferenciar-se em estômago partir de $4,70 \mathrm{~mm} \mathrm{CP}$ (não apresentou cecos pilóricos). Desde o estágio de pré-flexão, verificou-se três dobras intestinais e várias estrias no trato digestório. A análise da dieta revelou que as larvas menores (classe 1) apresentaram uma dieta distinta, com dominância de cladóceros (especialmente Bosmina hagmanni e Bosminopsis deitersi). Para a classe 2, o copépodo Notodiaptomus sp. foi importante tanto em número quanto em ocorrência, entretanto $B$. hagmanni, ainda teve participação significativa na dieta. Já as larvas maiores (classes 3,4$)$ e juvenis (classe 5) apresentaram uma dieta similar, consumindo principalmente os copépodos (Notodiaptomus sp.). Portanto, neste estudo as larvas de $C$. jenynsii podem ser consideradas zooplanctívoras, já que em todos os estágios de desenvolvimento, cladóceros e copédodos dominaram a dieta. As alterações na dieta acompanharam as modificações morfológicas dos estágios iniciais de C. jenynsii.

PALAVRAS-CHAVE. Linguado, alimentação inicial, aparelho digestório, desenvolvimento morfológico.

As espécies de peixes durante sua ontogenia inicial são submetidas a uma série de mudanças na sua morfologia (GisBert et al., 2002). No decorrer destas mudanças, as larvas passam por vários períodos cruciais para a sua sobrevivência, dentre os quais o mais relevante é o período de transição da alimentação endógena para a exógena (KAMLER, 1992; FUIMAN, 2002). Nesta fase, a sobrevivência e o crescimento das larvas estão fortemente ligados à disponibilidade de recursos alimentares adequados a sua primeira alimentação (SÁNChEZ-Velasco, 1998; SANTIN et al., 2004) e com o desenvolvimento de estruturas e órgãos necessários à alimentação (PORTER \& THEILACKER, 1999), como mudanças no trato digestório e formação da boca (MAKRAKIs et al., 2005).

Assim que eclodem, o trato digestório de muitas larvas de peixes é um tubo reto com extremidades fechadas e histologicamente indiferenciado ao longo de seu comprimento, permanecendo inalterado desde a abertura da boca até a absorção completa do vitelo (DABRowsKi, 1984; KolKovsKi, 2001). Logo, várias estruturas, como dobras intestinais, estômago e cecos, se desenvolvem, permitindo aumentar a eficiência de forrageamento (SANTin et al., 2004). Nesta fase, as larvas necessitam apresentar boca funcional para permitir a alimentação exógena (BLAXTER, 1988).

Sendo assim, o conhecimento do desenvolvimento inicial associado à primeira alimentação é essencial para o entendimento das interações tróficas que ocorrem no ambiente aquático, visto que as larvas de peixes são importantes consumidoras, realizando a transferência da produção primária para níveis tróficos mais elevados (NAKATANi et al., 2004), além de ajudar a identificar fatores limitantes na larvicultura. As informações sobre o aspecto alimentar nos estágios iniciais para espécies de peixes neotropicais, porém, são escassas (SANTIN et al., 2005; Borges et al. 2006; MAKRAKIs et al., 2005; 2008; SUIBERTO et al., 2009). 
Catathyridium jenynsii (Günther, 1862) (Achiridae), comumente conhecida como linguado, é uma espécie demersal de água doce, cuja distribuição se restringe à América do Sul, em rios da bacia do Paraná e do rio Uruguai (GraÇA \& Pavanelli, 2007). Convém ressaltar que esta espécie passou a ocupar regiões da bacia do alto rio Paraná apenas após a construção da hidrelétrica de Itaipu, com a consequente eliminação do Salto de Sete Quedas, que constituía uma barreira natural (JúLIO JÚNIOR et al., 2009).

Os primeiros estágios larvais do linguado são muito semelhantes aos dos peixes simétricos. A transformação das larvas acontece por meio da migração do olho que está relacionada com as alterações do habitat natural, de pelágico para demersal (Moser, 1996). Segundo NaKaTANi et al. (2001), no final do estágio de pósflexão as larvas de C. jenynsii passam de planctônicas para bentônicas. As transformações morfológicas de um plano simétrico para um assimétrico permitem que os linguados (espécies da ordem Pleuronectiformes) se escondam no substrato, protegendo-se de predadores, assim como possibilita um novo espectro de itens alimentares (OSSE \& VAN DEN BoogaART, 1997).

No presente estudo buscou-se descrever a morfologia do trato digestório de larvas de $C$. jenynsii, bem como, analisar os aspectos de sua alimentação no período larval e juvenil, a fim de responder às seguintes questões: 1) O trato digestório apresenta-se indiferenciado nos primeiros estágios larvais? 2) A dieta está relacionada ao grau de desenvolvimento da larva e ao desenvolvimento do trato digestório?

\section{MATERIAL E MÉTODOS}

A área de estudo compreendeu o reservatório de Itaipu $\left(24^{\circ} 059-25^{\circ} 339 \mathrm{~S} ; 54^{\circ} 009-54^{\circ} 379 \mathrm{~W}\right)$ localizado no rio Paraná, entre o Brasil e o Paraguai. O reservatório possui $151 \mathrm{~km}$ de extensão e ocupa uma área de $1.350 \mathrm{~km}^{2}$ (Agostinho et al., 1999).

As coletas foram realizadas em pontos de amostragem na margem esquerda do reservatório, nos rios Ocoí, São Francisco Verdadeiro, São Francisco Falso e no Arroio Guaçú (Fig. 1) nos meses de setembro de 2001 a março de 2002 e de setembro de 2002 a fevereiro de 2003. A amostragem ocorreu na região pelágica, por meio de arrastos horizontais $(20 \mathrm{~cm}$ de profundidade) por 10 minutos no período noturno (entre 19 e 23h), utilizando-se rede cônico-cilíndrica de malha $0,5 \mathrm{~mm}$ equipada com medidor de fluxo para medição do volume de água filtrada. O material coletado foi fixado em formol 4\% tamponado com carbonato de cálcio.

Os espécimes testemunho foram depositados na Coleção Ictiológica do Nupélia na Universidade Estadual de Maringá (NUP 14700).

No laboratório, as amostras foram triadas, quantificadas e identificadas ao nível específico, com base em NAKatAni et al. (2001). Posteriormente, para descrição do trato digestório, as larvas de C.jenynsii foram separadas de acordo com o grau de desenvolvimento: pré-flexão; flexão e pós-flexão, segundo a terminologia descrita por Ahlstrom \& BALL (1954), modificado por NAKATANI et al. (2001). As larvas e juvenis foram medidos quanto ao comprimento padrão $(\mathrm{CP})$, por meio de ocular micrométrica acoplada ao microscópio estereoscópico, e foram dissecados e analisadas quanto à morfologia. Uma câmara-clara acoplada ao microscópio foi utilizada para as ilustrações do trato digestório. Para análise da dieta, foi utilizado um total de 256 larvas e 16 juvenis de $C$. jenynsii. Para as larvas em estágio de pré-flexão e flexão analisou-se o conteúdo total do trato digestório e, para aquelas em estágio de pós-flexão e juvenil, analisou-se os dois terços iniciais do trato, devido ao grau de digestão na sua porção final. Os itens alimentares foram quantificados e identificados sob um microscópio estereoscópico e microscópio óptico. Os organismos zooplanctônicos foram identificados conforme a descrição de Koste (1978), SendaCZ \& Kubo (1982), ReID (1985), Matsumura-Tundisi (1986) e SEGERs (1995). O reconhecimento das algas foi baseada em REYNOLDS (1986).

Para calcular a frequência de ocorrência (FO\%) e numérica (FN\%) de cada item alimentar nas diferentes classes de comprimento padrão (CP), foram utilizados os métodos de ocorrência e numérico (HyNes, 1950; HysLOP, 1980). Foram estabelecidas as seguintes classes: $\mathrm{C} 1=3-3,9 \mathrm{~mm}$ (pré-flexão a inicio de flexão); $\mathrm{C} 2=4-4,9$ $\mathrm{mm}$ (início de flexão a flexão); C3=5-5,9 mm (início de pós-flexão); C4=6-6,9 mm (pós-flexão a final de pósflexão e C5>7-8,2 mm (juvenil).

Com o objetivo de estabelecer possíveis padrões na utilização dos recursos alimentares, foi empregada a Análise de Correspondência Destendenciada DCA (Hill \& GaUch, 1980) sobre os dados de frequência numérica dos recursos alimentares, considerando as classes de comprimento padrão. A análise foi conduzida no programa PC-ORD (MCCUNE \& MEFFoRD, 1997).

\section{RESULTADOS}

Mudanças na morfologia do trato digestório de C. jenynsii ocorreram desde os primeiros estágios de desenvolvimento até a fase juvenil (Figs 2-5). O estômago encontrou-se diferenciado a partir de $4,70 \mathrm{~mm}$ de comprimento padrão no estágio de pós-flexão, não apresentou cecos pilóricos e a região posterior do trato digestório aumentou relativamente em comprimento, apresentando-se bem desenvolvido no final do período larval e início de juvenil (Figs 4, 5).

Desde o estágio de pré-flexão, verificou-se no trato digestório três dobras intestinais e várias estrias (Fig. 2).

As larvas e juvenis de $C$. jenynsii consumiram algas, copépodos, cladóceros e rotíferos (Tab. I, Figs 6-10). A análise da dieta revelou que as larvas 


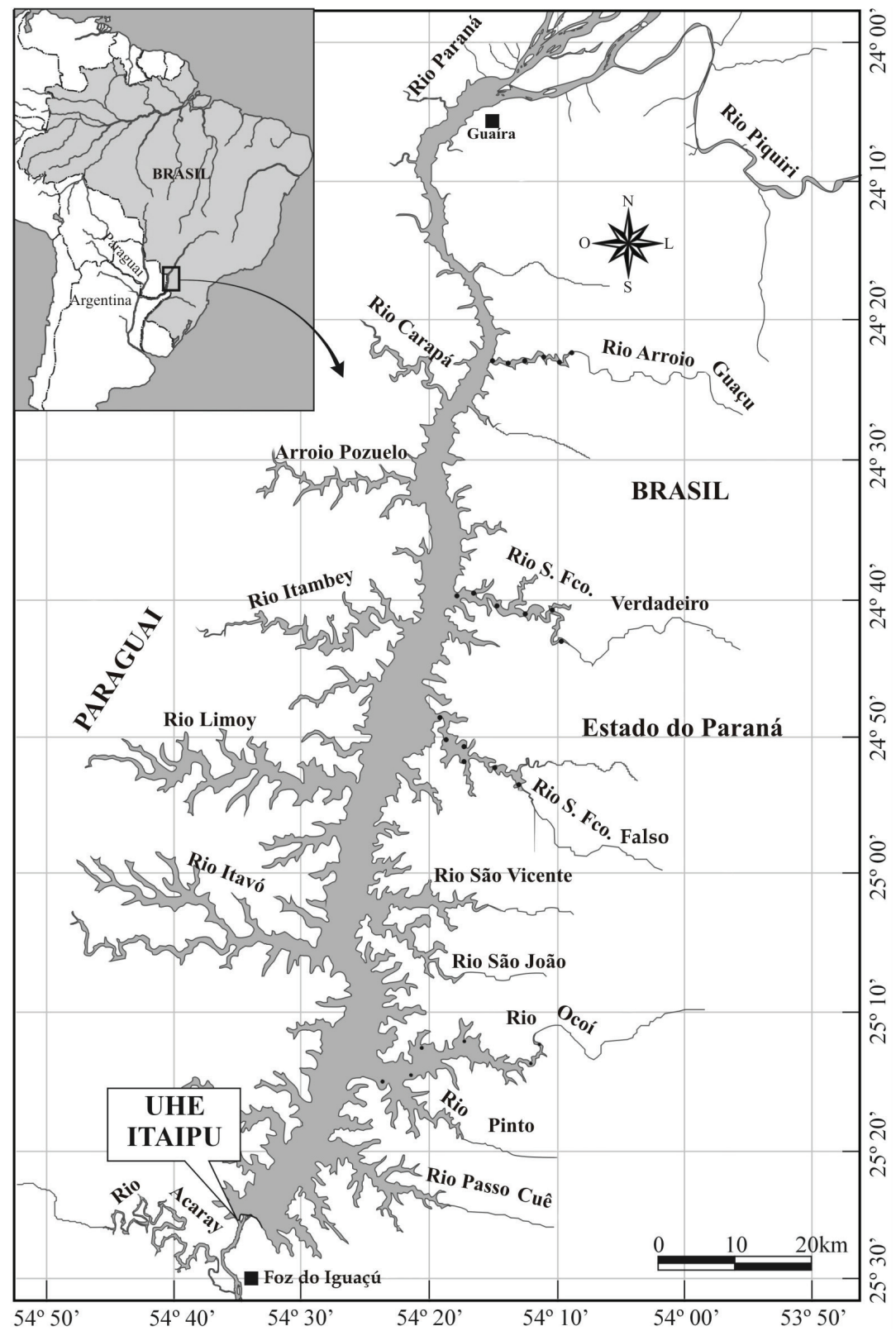

Fig. 1. Localização dos pontos de amostragem de Catathyridium jenynsii (Günther, 1862) no reservatório de Itaipu, rio Paraná, Brasil, de setembro de 2001 a março de 2002 e de setembro de 2002 a fevereiro de 2003. Círculos pretos, pontos de amostragens; quadrados pretos, municípios.

menores (classe 1) apresentaram uma dieta distinta, com dominância de cladóceros (especialmente Bosmina hagmanni e Bosminopsis deitersi), tanto em número quanto em ocorrência. Para a classe 2, o copépodo Notodiaptomus sp. foi importante tanto em número quanto em ocorrência, entretanto, B. hagmanni ainda teve participação significativa na dieta, com frequências numéricas de $24,5 \%$ e ocorrência de $36,56 \%$. As larvas maiores (classes 3 e 4 ) e os juvenis (classe 5) apresentaram uma dieta similar, consumindo principalmente copépodos (Notodiaptomus sp.), com frequências numéricas de $69,29 \%, 58,62 \%$ e $83,33 \%$, respectivamente (Figs 8-10). Os rotíferos estiveram presentes na dieta somente nas primeiras classes $(1,2 \mathrm{e} 3)$, enquanto que as algas estiveram presentes nas classes 2 e 4 , em baixas frequências. No final do período larval e começo do juvenil (classes 4 e 5), ocorreu uma diminuição no número de presas, visto que os juvenis apresentaram apenas três presas em sua dieta, sendo Notodiaptomus sp. a mais frequente (Fig. 10). As classes 1, 2 e 3 apresentaram, respectivamente, 12, 16 e 13 presas (Figs 6-8).

Os resultados da ordenação da dieta através da DCA (Figs 11, 12) foram interpretados particularmente pelo eixo 1 , o qual explicou a maior parte da variabilidade dos dados (autovalor $=0,43$ ). A distribuição dos pontos ao longo do eixo 1 mostra que a dieta foi distinta entre as classes de comprimento padrão. A ordenação das classes nos eixos da DCA mostrou dois grupos distintos: (1) classe 1 ; (2) classe 2, 3, 4 e 5 . Os recursos que mais influenciaram os escores a direita no eixo 1 foram $D$. brevirreme e B. calyciflorus, que foram consumidos somente pelos exemplares da classe 1 . 

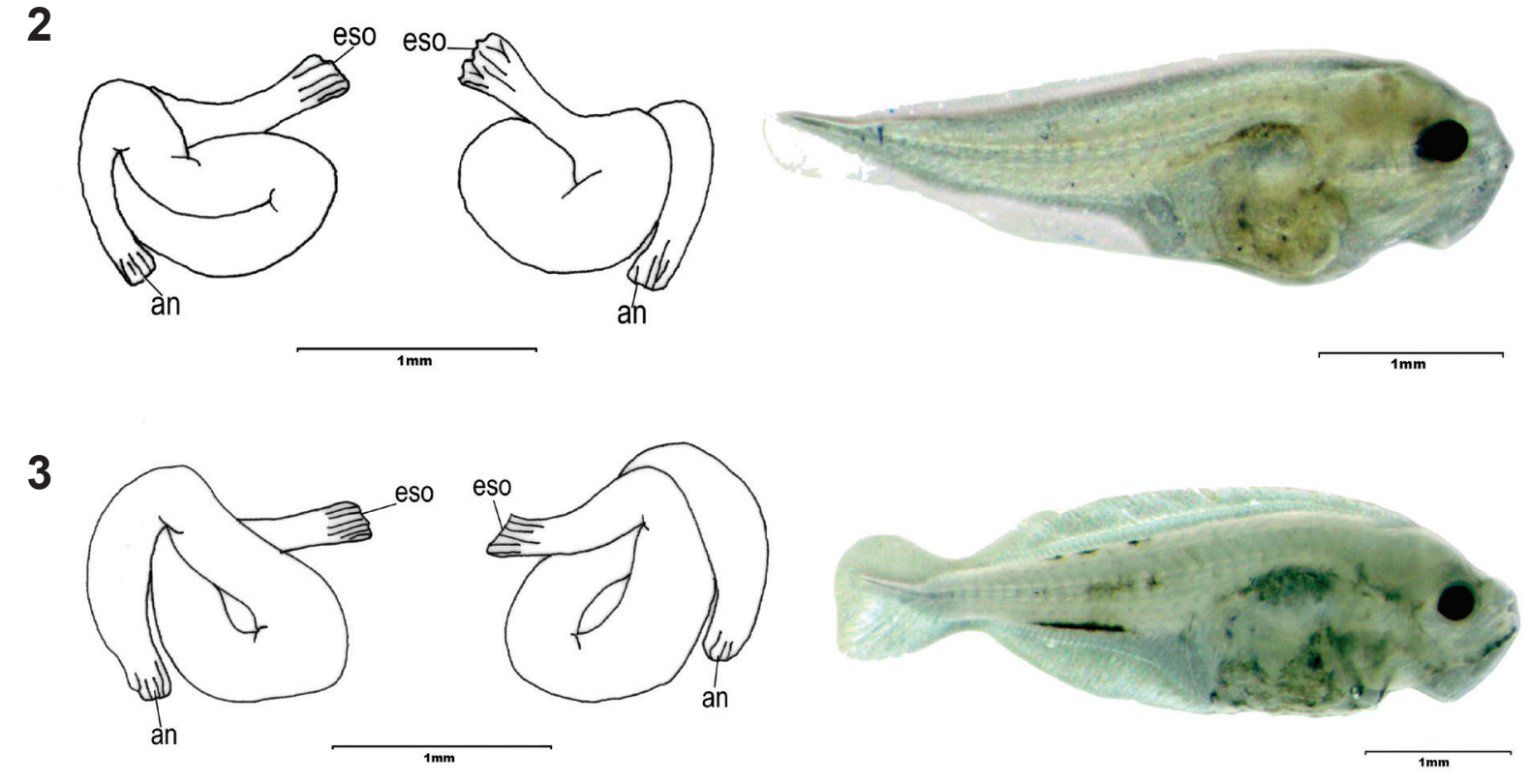

\section{4}
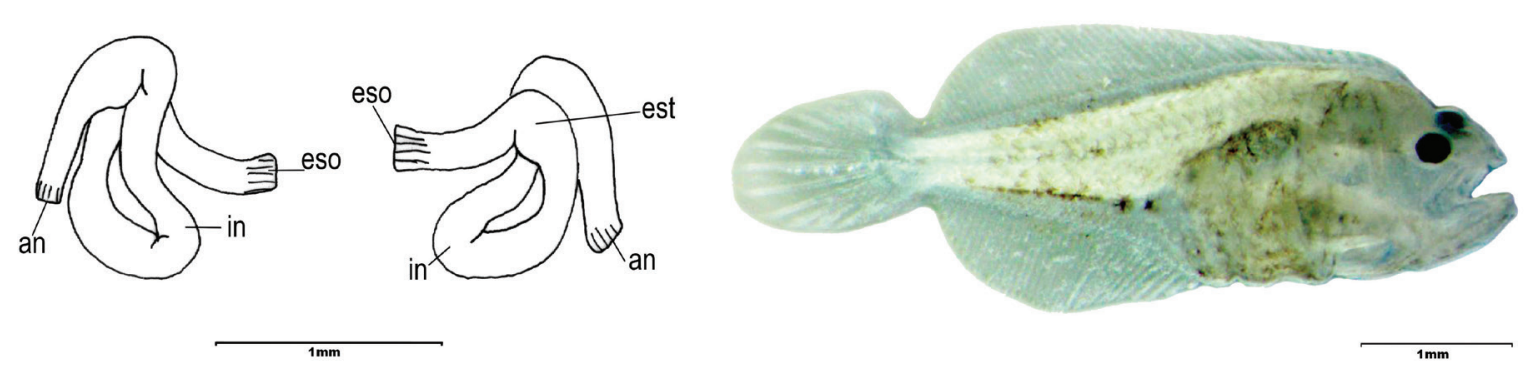

5
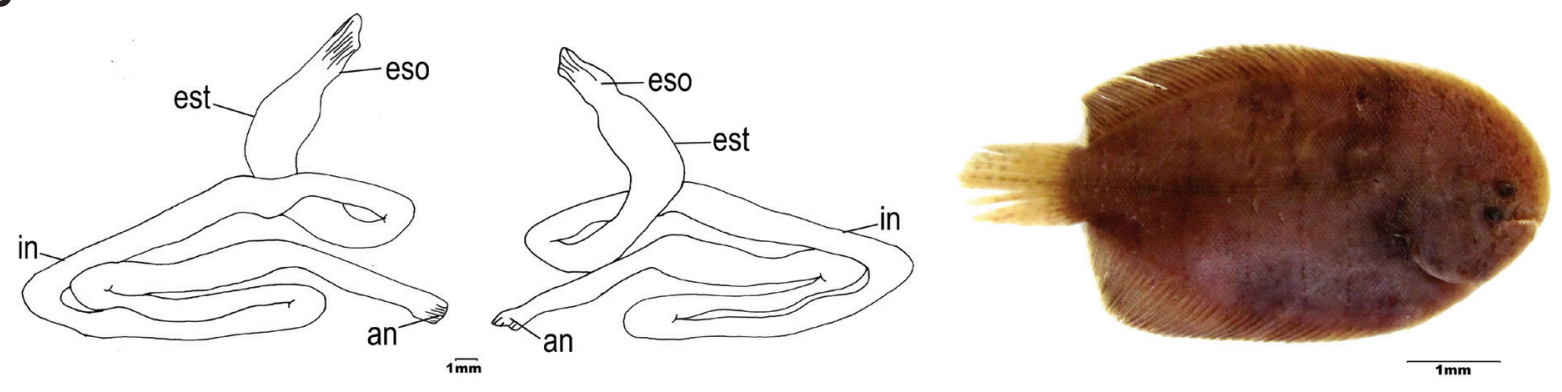

Figs 2-5. Mudanças no trato digestório de Catathyridium jenynsii (Günther, 1862) durante o desenvolvimento larval (à esquerda, desenho na orientação normal e à direita, desenho na orientação inversa): 2 , pré-flexão $(4,04 \mathrm{~mm}) ; 3$, flexão $(4,60 \mathrm{~mm}) ; 4$, pós-flexão $(4,70 \mathrm{~mm}) ; 5$, juvenil $(65,45 \mathrm{~mm})$ (eso, esôfago; est, estômago; in, intestino; an, ânus) no reservatório de Itaipu, rio Paraná, Brasil, de setembro de 2001 a março de 2002 e de setembro de 2002 a fevereiro de 2003.

\section{DISCUSSÃO}

$\mathrm{Na}$ espécie analisada, observou-se que o trato digestório encontra-se morfologicamente indiferenciado nos primeiros estágios de desenvolvimento (pré-flexão e flexão). Este padrão corrobora estudos feitos com outras espécies de peixes neotropicais (SANTIN et al., 2004; MAKrakis et al., 2005; Borges et al., 2006; SUIBERTO et al., 2009). Conforme Baldisserotto (2002), nesses estágios a digestão é muito rudimentar, sendo que o intestino apresenta-se curto e as células da mucosa intestinal são pouco diferenciadas.

As dobras intestinais observadas desde o estágio de pré-flexão têm como provável função auxiliar no processo de digestão, pois influenciam diretamente no tempo de passagem do alimento (BLAXTER, 1988; BALDISSEROTTO, 2002).

Somente no estágio de pós-flexão (aproximadamente 


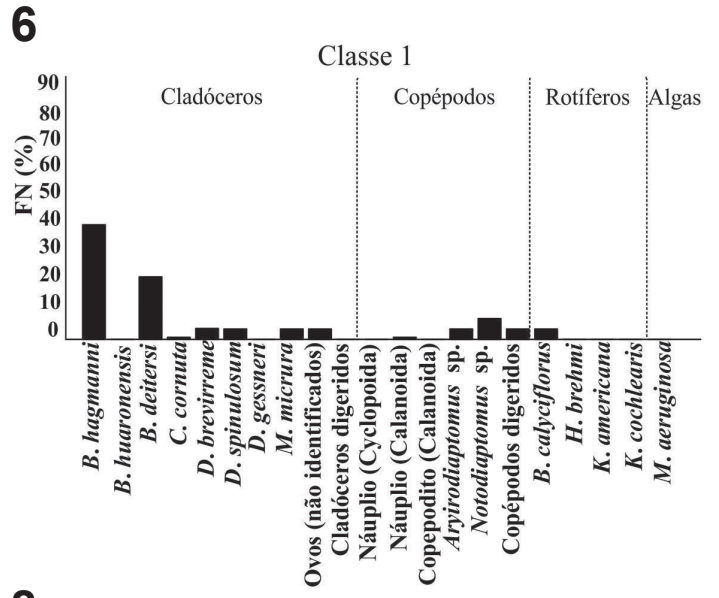

8

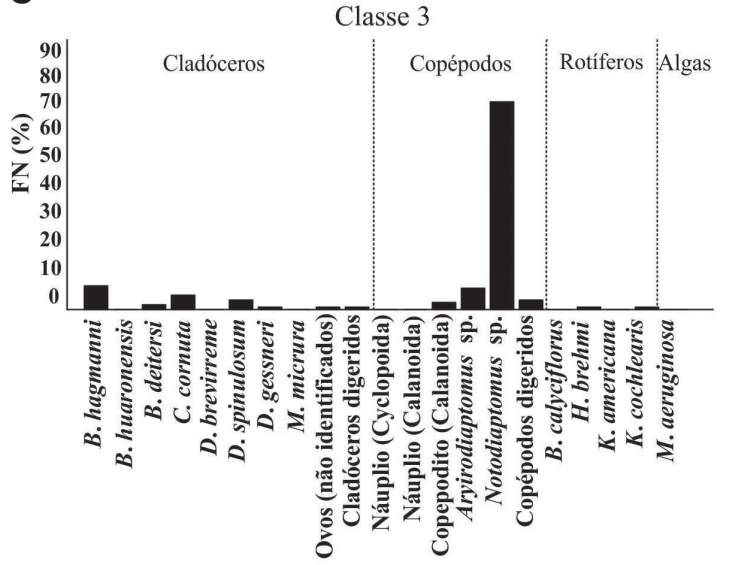

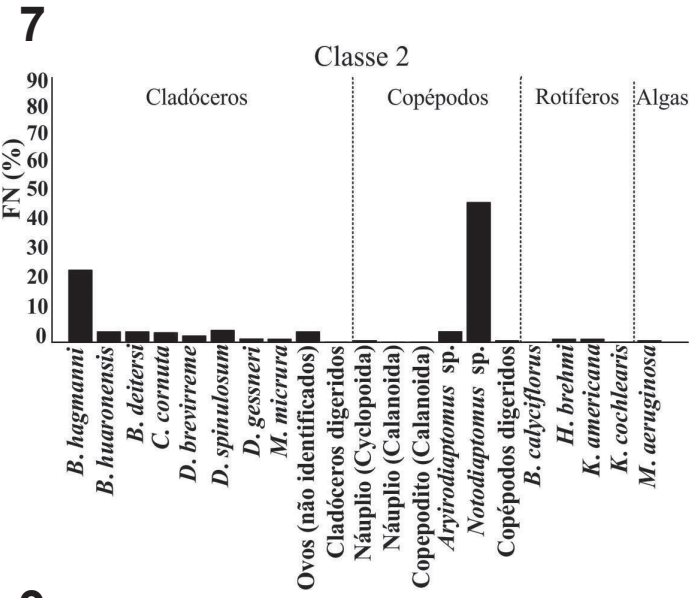

9

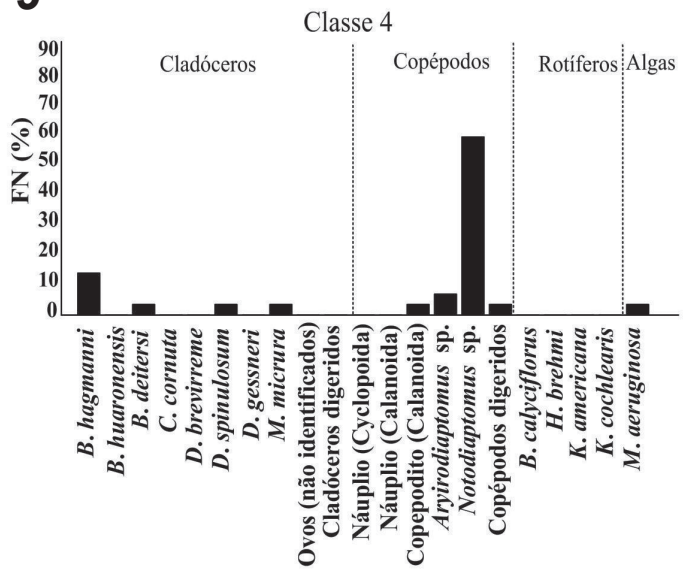

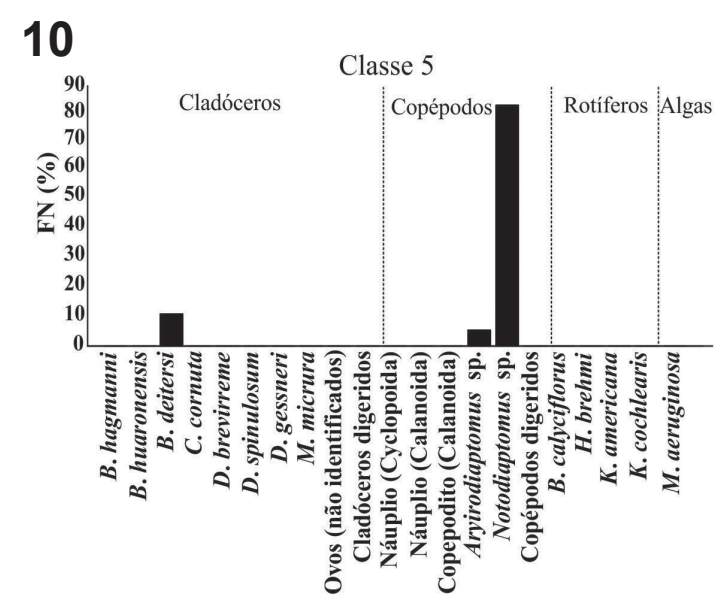

Figs 6-10. Frequência numérica (\%) dos itens alimentares em relação às classes de tamanho de Catathyridium jenynsii (Günther, 1862) no reservatório de Itaipu, rio Paraná, Brasil, de setembro de 2001 a março de 2002 e de setembro de 2002 a fevereiro de 2003.

4,70 mm de comprimento padrão) é que se observou um estômago diferenciado e, ainda assim, este não apresentou cecos pilóricos. O desenvolvimento de um estômago e de cecos pilóricos constitui a maior mudança morfológica no canal alimentar (Govoni et al., 1986). Pedersen \& FalK-Petersen (1992) relatam o desenvolvimento do estômago e dos cecos pilóricos na região de transição entre o esôfago e o intestino, o que foi verificado também para outras espécies, como por exemplo, Bryconamericus stramineus Eigenmann, 1908 (SUIBERTo et al., 2009). De acordo com DrewE et al. (2004), a relação entre a dieta e a estrutura e função dos cecos pilóricos é complexa e ainda mal compreendida.

Segundo MaKrakis et al. (2005), modificações morfológicas no trato digestório resultam em mudanças na dieta, pois permitem a captura de presas possivelmente maiores e energeticamente mais ricas. Não obstante, neste estudo, houve mudanças na dieta de larvas de $C$. jenynsii concomitante ao seu desenvolvimento e ao de seu trato digestório. A dieta de larvas menores (classe 1), com o trato indiferenciado, constituiu-se principalmente de cladóceros Bosmina hagmanni e Bosminopsis deitersi, 
Tab. I. Frequência de ocorrência (FO\%) e numérica (FN\%) dos itens alimentares registrados no trato digestório de larvas e juvenis de Catathyridium jenynsii (Günther, 1862) nas diferentes classes de comprimento padrão $(\mathrm{C} 1,2,3,4$ e 5) no reservatório de Itaipu, rio Paraná, Brasil, entre setembro de 2001 e março de 2002 e entre setembro de 2002 a fevereiro de 2003. n=número de exemplares analisados.

\begin{tabular}{|c|c|c|c|c|c|c|c|c|c|c|}
\hline \multirow[b]{3}{*}{ Itens alimentares } & \multicolumn{8}{|c|}{ Larvas } & \multirow{2}{*}{\multicolumn{2}{|c|}{$\begin{array}{c}\text { Juvenis } \\
\text { C5 }(n=16)\end{array}$}} \\
\hline & \multicolumn{2}{|c|}{$\mathrm{C} 1(\mathrm{n}=13)$} & \multicolumn{2}{|c|}{$\mathrm{C} 2(\mathrm{n}=134)$} & \multicolumn{2}{|c|}{$\mathrm{C} 3(\mathrm{n}=94)$} & \multicolumn{2}{|c|}{$\mathrm{C} 4(\mathrm{n}=21)$} & & \\
\hline & $\mathrm{FO} \%$ & FN\% & $\mathrm{FO} \%$ & FN\% & $\mathrm{FO} \%$ & FN\% & $\mathrm{FO} \%$ & FN\% & $\mathrm{FO} \%$ & FN\% \\
\hline \multicolumn{11}{|l|}{ CLADÓCEROS } \\
\hline Bosmina hagmanni & 84,61 & 39,28 & 36,56 & 24,5 & 10,63 & 7,87 & 19,04 & 13,79 & 0 & 0 \\
\hline Bosmina haruoensis & 0 & 0 & 5,22 & 3,5 & 0 & 0 & 0 & 0 & 0 & 0 \\
\hline Bosminopsis deitersi & 86,15 & 21,43 & 5,22 & 3,5 & 2,12 & 1,57 & 4,76 & 3,49 & 12,5 & 11,11 \\
\hline Ceriodaphnia cornuta & 7,7 & 3,57 & 0,74 & 0,5 & 3,19 & 2,36 & 4,76 & 3,49 & 0 & 0 \\
\hline Diaphanosoma brevirreme & 15,38 & 7,14 & 3,73 & 2,5 & 2,12 & 1,57 & 0 & 0 & 0 & 0 \\
\hline Diaphanosoma spinulosum & 7,7 & 3,57 & 5,97 & 4 & 4,25 & 3,15 & 4,76 & 3,49 & 0 & 0 \\
\hline Daphnia gessneri & 0 & 0 & 1,49 & 1 & 1,06 & 0,79 & 0 & 0 & 0 & 0 \\
\hline Moina micrura & 7,7 & 3,57 & 1,49 & 1 & 0 & 0 & 4,76 & 3,49 & 0 & 0 \\
\hline Ovos (não identificados) & 7,7 & 3,57 & 5,22 & 3,5 & 1,06 & 0,79 & 0 & 0 & 0 & 0 \\
\hline Cladóceros digeridos & 0 & 0 & 0 & 0 & 1,06 & 0,79 & 0 & 0 & 0 & 0 \\
\hline \multicolumn{11}{|l|}{ COPÉPODOS } \\
\hline Náuplio (Cyclopoida) & 0 & 0 & 0,74 & 0,5 & 0 & 0 & 0 & 0 & 0 & 0 \\
\hline Náuplio (Calanoida) & 0 & 0 & 0,74 & 0,5 & 0 & 0 & 0 & 0 & 0 & 0 \\
\hline Copepodito calanoida & 0 & 0 & 0 & 0 & 3,19 & 2,36 & 4,76 & 3,49 & 0 & 0 \\
\hline Aryirodiaptomus sp. & 7,7 & 3,57 & 6,91 & 3,57 & 9,57 & 7,08 & 9,52 & 6,89 & 6,25 & 5,55 \\
\hline Notodiaptomus sp. & 15,38 & 7,14 & 70,89 & 47,5 & 93,62 & 69,29 & 80,95 & 58,62 & 93,75 & 83,33 \\
\hline Copépodos digeridos & 7,7 & 3,57 & 0,74 & 0,5 & 4,25 & 3,15 & 4,76 & 3,49 & 0 & 0 \\
\hline \multicolumn{11}{|l|}{ ROTÍFEROS } \\
\hline Brachionus calyciflorus & 7,7 & 3,57 & 0 & 0 & 0 & 0 & 0 & 0 & 0 & 0 \\
\hline Horaella brehmi & 0 & 1,49 & 1 & 1,06 & 0,79 & 0 & 0 & 0 & 0 & \\
\hline Keratella americana & 0 & 0 & 1,49 & 1 & 0 & 0 & 0 & 0 & 0 & 0 \\
\hline Keratella cochlearis & 0 & 0 & 0 & 0 & 1,06 & 0,79 & 0 & 0 & 0 & 0 \\
\hline \multicolumn{11}{|l|}{ ALGAS } \\
\hline Microcystis aeruginosa & 0 & 0 & 0,74 & 0,5 & 0 & 0 & 4,76 & 3,49 & 0 & 0 \\
\hline
\end{tabular}

porém, em larvas maiores (classes 2, 3 e 4) e também em juvenis (classe 5), com o trato provavelmente já diferenciado, os copépodos Notodiaptomus sp. passaram a predominar na dieta. Além da transição do consumo de presas menores para as maiores, como os copépodos, notou-se uma diminuição no espectro de tipos de presas consumidas. Tais resultados reforçam a hipótese de que as larvas de peixes tentam maximizar o ganho de energia disponível a fim de compensar os gastos de energia com ataques, captura, ingestão e manipulação do alimento (Beyer, 1980; PyKe, 1984; AdriaEns et al., 2001; NunN et al., 2012).

Embora as mudanças na dieta estejam diretamente relacionadas ao desenvolvimento do trato digestório, outros atributos das larvas, como o tamanho da boca (que limita o tamanho de presa a ser consumida), diferenças na anatomia oral (posição da boca, dentes e rastros branquiais), acuidade visual, motilidade e o modo de forrageamento também podem interferir na alimentação dos peixes (MAKRAKIs et al., 2008). De acordo com ABELHA et al. (2001), dietas distintas dentro de uma mesma espécie são frequentemente encontradas conforme os estágios de desenvolvimento dos indivíduos, decorrentes de diferenças na demanda energética e nas limitações morfológicas. Assim, presume-se que as transformações morfológicas podem determinar a dieta de uma espécie, pois definem a maneira como esta explora o alimento e o que pode comer.

Para Osse \& VAN DEN BoogaART (1997), as transformações morfológicas do linguado de um plano simétrico para um assimétrico permitem que estas espécies explorem um novo espectro de itens alimentares. Esta afirmação também explica as mudanças na dieta (de cladórecos para copépodos) ao longo do desenvolvimento larval.

Neste estudo, os juvenis e as larvas de $C$. jenynsii, 

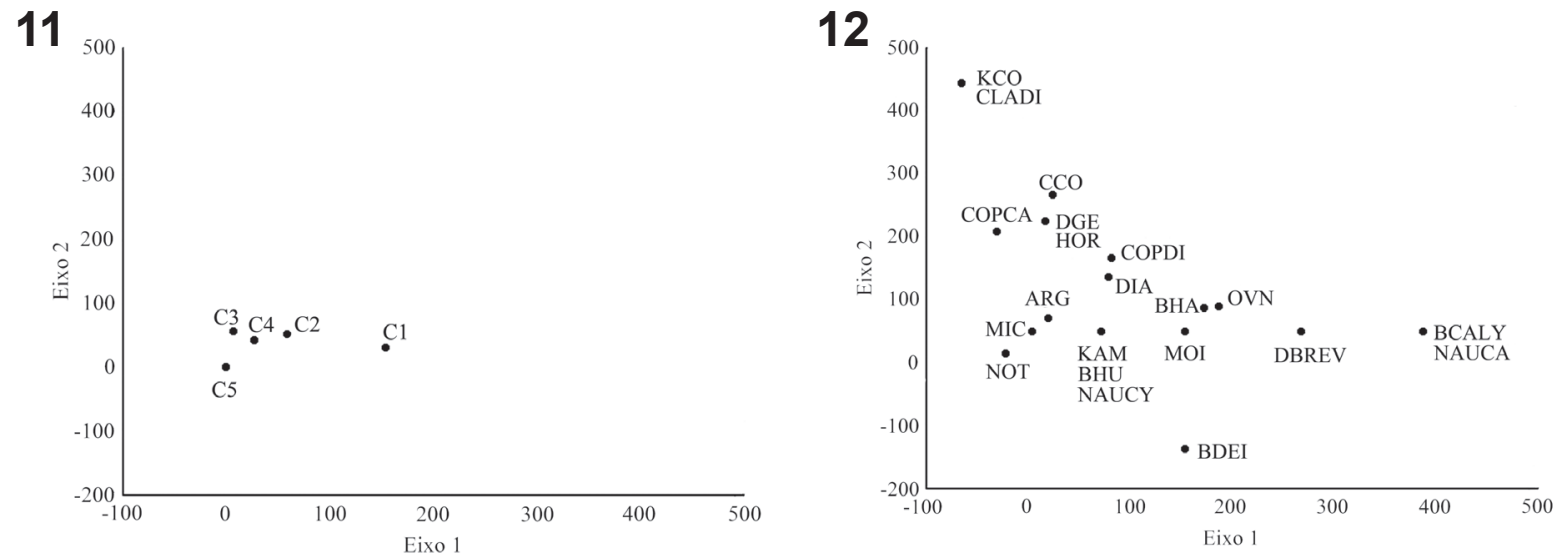

Figs 11, 12. Ordenação das classes de comprimento padrão (11) e frequência de numérica para cada item alimentar (12) de Catathyridium jenynsii (Günther, 1862) no reservatório de Itaipu, rio Paraná, Brasil, de setembro de 2001 a março de 2002 e de setembro de 2002 a fevereiro de 2003 , ao longo dos eixos 1 e 2 da Análise de Correspondência Destendenciada (DCA) (ARG, Argyrodiaptomus sp.; BCALY, Brachionus calyciflorus; BDEI, Bosminopsis deitersi; BHU, Bosmina huauriensis; CCO, Ceriodaphnia cornuta; CLADI, cladócero digerido; COPCA, copepodito de Calanoida; COPDI, copépodo digerido; DBREV, Diaphanosoma brevirreme; DGE, Daphnia gessneri; DIA, Diaphanosoma spinulosum; HOR, Horaella brehmi; KAM, Keratella americana; KCO, Keratella cochlearis; MIC, Microcystis aeruginosa; MOI, Moina micrura; NAUCY, náuplio de Cyclopoida; NOT, Notodiaptomus sp.; OVN, ovos não identificados; NAUCA, náuplio de calanoida).

em suas diferentes fases de desenvolvimento, podem ser consideradas zooplânctívoras, já que não foram registrados itens de categorias tróficas diferentes. Em adultos desta espécie, os peixes predominam na dieta (HAHN et al., 2004). Vale ressaltar que a presença de algas na dieta das larvas da espécie aqui estudada pode ser considerada acidental, já que este item foi consumido apenas pelos indivíduos das classes 2 e 4, sempre em baixas frequências. Tal suposição é consistente com a afirmação de SuIBERTo et al. (2009), que assegura que a presença de algas no estômago de larvas mais desenvolvidas, com alta capacidade de predação, ocorre com a captura de presas maiores.

Os resultados obtidos mostram que a dieta do $C$. jenynsii está intimamente relacionada ao crescimento da larva, associado ao desenvolvimento do trato digestório. Vale ressaltar que o conhecimento das fontes de energia utilizadas pelas larvas de peixes é essencial para a prática eficiente da piscicultura e, segundo LeITE \& ARAUJOLiMA (2000), fornece também informações ecológicas quanto ao papel das espécies no ecossistema, sendo um conhecimento imprescindível à conservação.

Agradecimentos. Os autores agradecem à Itaipu Binacional pelo apoio logístico e financeiro para a realização da pesquisa.

\section{REFERÊNCIAS BIBLIOGRÁFICAS}

Abelha, M. C. F.; Agostinho, A. A. \& Goulart, E. 2001. Plasticidade trófica em peixes de água doce. Acta Scientiarum 23:425-434.

Adriaens, D.; Aerts, P. \& Verraes, W. 2001. Ontogenetic shift in mouth opening mechanisms in catfish (Clariidae, Siluriformes) A response to increasing functional demands. Journal of Morphology 247:197-216.

Agostinho, A. A.; Okada, E. K. \& Gregoris, J. A. 1999. A pesca no reservatório de Itaipu: Aspectos socioeconômicos e impactos do represamento. In: HenRY, R. ed. Ecologia de reservatórios: Estrutura, função e aspectos sociais. Botucatu, FAPESP. p.281319.

Ahlstrom, E. H. \& Ball, O. P. 1954. Description of eggs and larvae of jack mackerel (Trachurus symetricus) and distribuition and abundance of larvae in 1950 and 1951. Fishery Bulletin 56:209245.

BALDISSEROTTO, B. 2002. Fisiologia de peixes aplicada à piscicultura. Santa Maria, UFSM. 212p.

BEyER, J. E. 1980. Feeding success of clupeoid fish larvae and stochastic thinking. Dana 1:65-91.

BLAXTER, J. H. S. 1988. Pattern and variety in development. In: HoAR, W. S. \& Randall, D. J. eds. Fish Physiology. London, Academic Press. p.1-58.

Borges, R. Z.; Assakawa, L. F.; Cunha. A. B.; Bialetzki, A. \& NaKatani, K. 2006. Morfologia do trato digestório e dieta de larvas de Bryconamericus aff. iheringii (Boulenger, 1887) (Osteichthyes, Characidae). Acta Scientiarum, Biological Sciences 28(1):51-57.

DABRowsKi, K. R. 1984. The feeding of fish larvae: present "state of the art" and perspectives. Reproduction Nutrition Development 24(6):808-833.

Drewe, K. E.; Horn, M. H.; Dickson, K. A. \& Gawlicka, A. 2004. Insectivore to frugivore changes in gut morphology and digestive enzyme activity in the characid fish Brycon guatemalensis from Costa Rica forest streans. Journal Fish Biology 64(4):890-902.

Fuiman, L. A. 2002. Special considerations of fish eggs and larvae. In: Fuiman, L. A. \& Werner, R. G. eds. Fishery science: the unique contributions of early life stages. Oxford, Blackwell Science. p.1-32.

Gisbert, E.; Merino, G.; Muguet, J. B.; Bush, D.; Piedrahita, R. H. \& Conklin, D. E. 2002. Morphological development and growth patterns in hatchery-read California halibut larvae. Journal of Fish Biology 61:1217-1229.

Govoni, J. J.; Boehlert, G. W. \& Watanabe, Y. 1986. The physiology of digestion in fish larvae. Environmental Biology of Fish 16(13):59-77

Graça, W. J. \& Pavanelli, C. S. 2007. Peixes da planície de inundação do alto rio Paraná e áreas adjacentes. Maringá, Eduem. 241p.

Hahn, N. S.; Fugi, R. \& Andrian, I. F. 2004. Trophic ecology of the fish assemblages. In: Thomaz, S. M.; Agostinho, A. A. \& Hahn, N. S. eds. The upper Paraná river and its floodplain physical aspects, ecology and conservation. Leiden, Backhuys Publishers. p.247-259.

Hill, M. O. \& Gauch, H. G. 1980. Detrended Correspondence Analysis, an improved ordination technique. Vegetatio 42:47-58.

HyNES, H. B. N. 1950. The food of freshwater sticklebacks (Gasterosteus aculeatus and Pigosteus pungitius), with a review of methods used in studies of the food of fishes. Journal of Animal Ecology 19:36-56.

HysLop, E. J. 1980. Stomach contents analysis: a review of methods and their application. Journal of Fish Biology 17:411-429.

Júlio Júnior, H. F.; Deitós, C.; Agostinho, A. A. \& Pavanelli, C. S 
2009. A massive invasion of fish species after eliminating a natural barrier in the upper rio Paraná basin. Neotropical Ichthyology 7(4):709-718

KAMLER, E. 1992. Early life history of fish: an energetics approach. London, Chapman \& Hall. 267p.

Kolkovski, S. 2001. Digestive enzymes in fish larvae and juveniles: implications and applications to formulated diets. Aquaculture 200:181-201.

Koste, W. 1978. Rotatoria. Die Rädertiere Mitteleuropas. Ein Bestimmungswerk, begründet von Max. Voigt Überordnung Monogononta. Berlim, Gebrüder Bornetraeger. 673p.

Leite, R. G. \& Araúso-Lima, C. A. R. M. 2000. A dieta das larvas de Mylossoma aureum e Mylossoma duriventre na Amazônia Central. Acta Amazonica 30(1):129-147.

Makrakis, M. C.; Nakatani, K.; Bialetzki, A.; Gomes, L. C.; Sanches, P. V. \& Baumgartner, G. 2008. Relationship between gape size and feeding selectivity of fish larvae from a Neotropical Reservoir. Journal Fish of Biology 72(7):1690-1707.

Makrakis, M. C.; Nakatani, K.; Bialetzki, A.; Sanches, P. V.; Baumgartner, G. \& Gomes, L. C. 2005. Ontogenetic shifts in digestive tract morphology and diet of fish larvae of the Itaipu Reservoir, Brazil. Environmental Biology of Fishes 72:99-107.

Matsumura-Tundisi, T. 1986. Latitudinal distribuition of Calanoida copepodos in freshwater aquatic systems of Brazil. Revista Brasileira de Biologia 46(3):527-553

McCune, B. \& Mefford, M. J. 1997. PC-ORD. Multivariate Analysis of Ecological Data. Version 3.0. Oregon, Gleneden Beach, MjM Software.

Moser, H. G. 1996. The early stages of fishes in the California Current Region. California Cooperative Ocean Fisheries Investigations (CALCOFI). ATLAS N 33. Lawrence, Allen Press. $1505 \mathrm{p}$.

Nakatani, K.; Agostinho, A. A.; Baumgartner, G.; Bialetzki, A.; Sanches, P. V.; Makrakis, M. C. \& Pavanelli, C. S. 2001. Ovos e larvas de peixes de água doce: desenvolvimento e manual de identificação. Maringá, EDUEM. 378p.

Nakatani, K.; Bialetzki, A.; Baumgartner, G.; Sanches, P. V. \& MaKrakis, M. C. 2004. Temporal and spatial dynamics of fish eggs and larvae. In: Thomaz, S. M., Agostinho, A. A. \& Hahn, N. S. eds. The Upper Paraná River Floodplain: physical aspects, ecology and conservation. Leiden, Backhuys Publishers. p.1-30.

Nunn, A. D.; Tewson, L. H. \& Cowx, I. G. 2012. The foraging ecology of larval and juvenile fishes. Reviews in Fish Biology and Fisheries 22:377-408
Osse, J. W. M. \& Van den Boogaart, J. G. M. 1997. Size of flatfish larvae at transformation, functional demands and historical constraints. Journal of Sea Research 37:229-239.

Pedersen, T. \& Falk-Petersen, I. B. 1992. Morphological changes during metamorphosis in cod (Gadus morhua L.) with particular refernce to development of the stomach and pyloric caeca. Journal of Fish Biology 41:449-461.

Porter, S. M. \& Theilacker, G. H. 1999. The development of the digestive tract an eye in larval walleye pollock, Theragra chalcogramma. Fishery Bulletin 97(3):722-729.

PyKe, G. H. 1984. Optimal foraging theory: a critical review. Annual Review of Ecology, Evolution, and Systematics 15:523-575.

ReID, J. W. 1985. Chave de identificação e lista de referências bibliográficas para as espécies continentais sulamericanas de vida livre da ordem Cyclopoida (Crustacea, Copepoda). Boletim de Zoologia 9:17-143.

Reynolds, C. S. 1986. The ecology of freshwater phytoplankton. Cambridge, Cambridge Unversity Press. 384p.

Sánchez-Velasco, L. 1998. Diet composition and feeding habits of fish larvae of two co-occurring species (Pisces: Callionymidae and Bothidae) in the North-western Mediterranean. ICES (Int. Conc. Explor. Sea). Journal of Marine Science 55:299-308.

Santin, M.; BialetzKi, A. \& NaKatani, K. 2004. Mudanças ontogênicas no trato digestório e na dieta de Apareiodon affinis (Steindachner, 1879) (Osteichthyes, Parodontidae). Acta Scientiarum, Biological Sciences 26(3):291-298.

Santin, M.; Di Benedetto, M.; Bialetzki, A.; Nakatani, K. \& Suiberto, M. R. 2005. Aspectos da dieta de larvas de Astyanax janeiroensis (Eigenmann, 1908) (Osteichthyes, Characidae) no reservatório de Uaricana, Rio Arraial, Estado do Paraná. Boletim do Instuto da Pesca 31(1):73-80.

SEgERS, H. 1995. Rotifera. 2. The Lecanidae (Monogononta). In: Dumont, H. J. F. ed. Guides to the identification of the microinvertebrates of continental waters of the world. Netherlands, SPB Academic Publishing. 226p.

Sendacz, S. \& Kubo, E. 1982. Copepoda (Calanoida e Cyclopoida) de reservatório do Estado de São Paulo. Boletim do Instituto da Pesca 9:51-89.

Suiberto, M. R.; Galuch, A. V.; Bialetzki, A. \& Nakatani, K. 2009. Ontogenetic shifts in the digestive tube and diet of Bryconamericus stramineus Eigenmann, 1908 (Osteichthyes, Characidae). Acta Limnologica Brasiliensia 21(4):465-472. 